\title{
The Impact of Environmental Tax on Low-Carbon Transition
}

\author{
Meng Liu \\ PhD Student \\ School of Economics \\ Central University of Finance and Economics \\ China
}

\begin{abstract}
This study examines endogenous and directed technical change with environmental tax basing on Aghion and Howitt (1998) growth model. We show that the tax policy with enough tax rate could effectively contribute to lowcarbon transition. We also find that: (1) using the tax revenue to subsidy clean technology development could reduce minimum tax rate and correct the distortion of tax revenue to economic. (2) levying tax on "dirty" production mighthold back economic development, increase related household expenditure and often the influence on low-income group is higher than on the high-income family. (3) these negative impacts of environmental tax might be gradually alleviated by long-term tax policy implementation.
\end{abstract}

Keywords: Environmental tax; Endogenous model; Low-carbon transition; Wealth Distribution Effect.

\section{Introduction}

The issue of climate change has become an important challenge in the world. With population and economic development, carbon dioxide-based greenhouse gas emissions are the main cause of climate warming. Without effective emission reduction, global atmospheric temperatures may increase about $2.5^{\circ} \mathrm{C}$ to $7.8^{\circ} \mathrm{C}$ by the end of the century (IPCC-AR5, 2013). It results inthe increase of sea level, ecological damage, increased extreme weather, which might seriously threaten the survival and development of human beings, especially for some countries where located in low altitude or tropics area. In response to this huge threat, more and more countries have joined the cooperation agreement on climate change to accelerate the global transition to a green and lowcarbon sustainable development. According to the plan of the Paris Agreement, at the end of the century, the global average temperature should be controlled to rise less than $2{ }^{\circ} \mathrm{C}$ before industrialization. The key to climate governance and carbon emission control is to change the economic development mode that was supported by high carbon emissions in the past and transform to a low-carbon model.

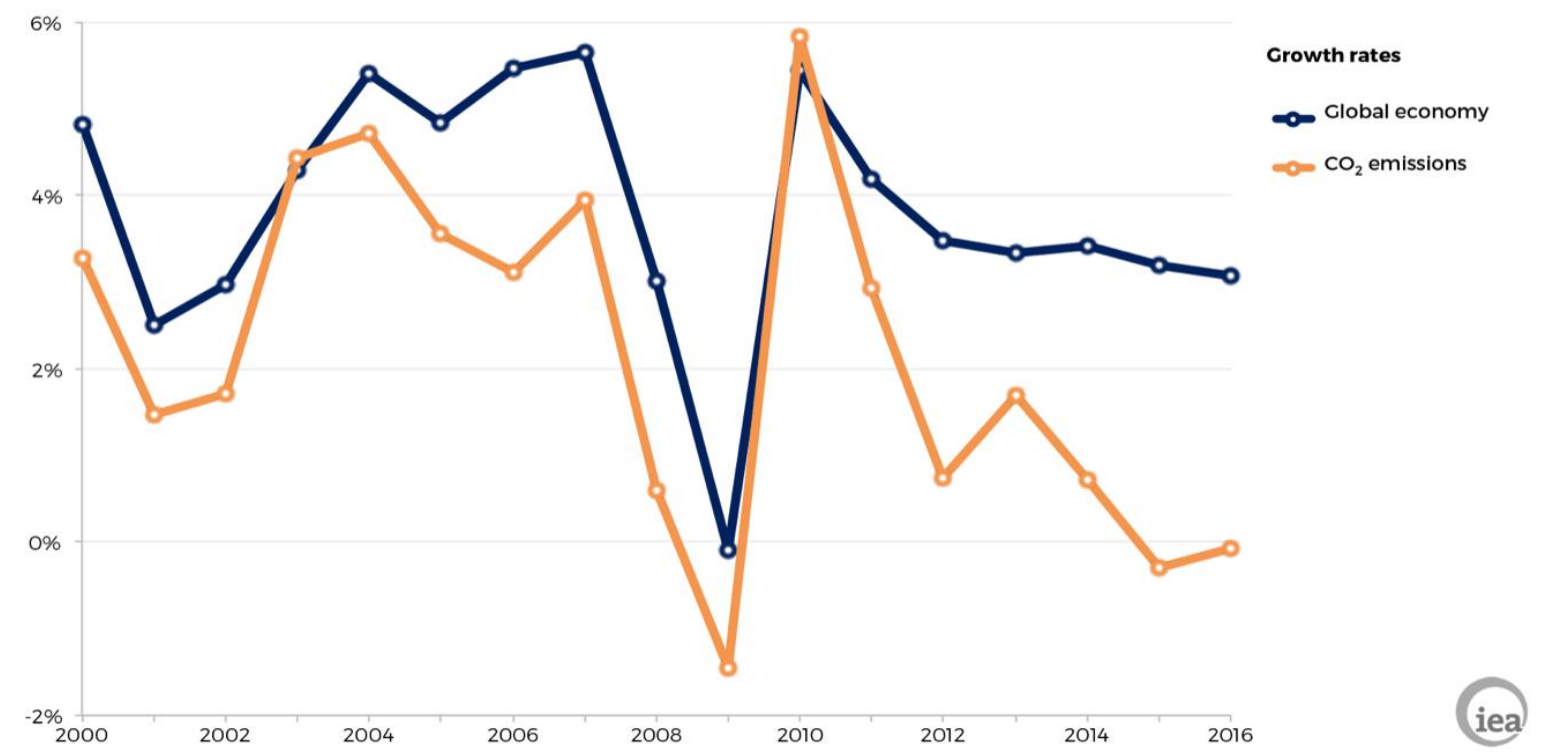

Figure 1, Comparison of economic growth rate and CO2 emission growth rate in 2000-2016IEA, 2017) 
As shown in Figure 1, global carbon dioxide emissions have barely increased in the past three years since 2014, with an average GDP growth of 3\% (IEA, 2017). Specifically, the United States' carbon dioxide emissions in 2016 fell by $3 \%$. The reduction was mainly attributed to the gradual improvement of the low-carbon market, the replacement of coal by natural gas, technological development, and the decline in costs of new energy resources such as solar and wind power. The EU countries have implemented low-carbon policies earlier, but due to bottlenecks in the development of renewable energy, the speed of emission reduction has been hindered. China's carbon dioxide emissions in 2016 decreased by $1 \%$, but unlike Europe and the United States, China's emission reduction mainly comes from the suspension of construction of coal-fired power units driven by air pollution control policies. To reach the Paris Agreement, reaching the peak of carbon emissions by 2030 depends on a large amount of green investment to accelerate the development of low-carbon transition.

\section{Literature review}

Many researches have studies how the government makes appropriate climate policy in order to cope with this situation, and the core of the climate policy is how to create the most environmental benefits with minimal cost. Among the many climate policies, the pollution tax policy is one of the most effective instruments in terms of comprehensive consideration of effectiveness, low cost and promotion of low carbon development. Most of the pollution tax policies are imposed on pollution caused by the use of energy sources such as fossil fuels, which increase the use price of fossil fuels in disguise, thereby suppressing the use of such energy sources and promoting the development of clean alternative energy sources.

Many studies have shown that changes in fossil fuel-related prices will effectively drive the development of clean low-carbon technologies. Most of the early research focused on the relationship between the price of fossil fuels and clean technology, and proved that price factors are driving the development of clean technology. Newell et al (1999) found that the rise in oil prices has led to more research and development in air conditioning from the reduction of air-conditioning costs to the study of energy efficiency. The study by Popp (2002) and Hassler et al (2011) find the impact of energy prices on the development of low-energy technologies. In recent years, as people pay more and more attention to climate issues, articles about the relationship between economic development and climate change are increasing, and the focus of research is more on the role of climate policies such as pollution tax on low-carbon transformation. Acemoglu et al (2012) indicate that the carbon tax on pollution production could promote clean technology development in the long run and avoid environmental disasters. The optimal policy is a combination of carbon tax and clean energy subsidies. Aghion et al's (2016) follow-up empirical study of the US automotive industry finds that the positive role of different pollution tax policies in clean technology innovation. However, most of above tax policy studies have not pay enough attention on the role of capital, which is undoubtedly very important in the development of low-carbon technology. At this point, Aghion and Howitt's $(1992,1998)$ model of destruction innovation emphasizes the vital role that capital and innovation play together in the long-term development of the economy, and the interaction between the two, therefore it is suitable for a research framework of low carbon transformation. This paper introduces the pollution tax policy into the endogenous economic growth model of Aghion and Howitt (1998), and studies the factors that need to be considered when formulating a pollution tax policy in the context of a clean and polluting production enterprise in the economy, and for low carbon. The driving role of transformation. In addition, policy costs cannot be ignored when discussing the positive influence of the pollution tax policy. The most direct impact is the increase in energy use prices due to taxation, which will be passed on to household energy expenditures (e.g. heating, lighting, etc.). The impact of wealth distribution caused by the increase in energy expenditure has different impacts on different groups of people, and there are not many related studies. According to the data of the UK National Bureau of Statistics (2008), the energy expenditure of the $20 \%$ lowest income population in the UK is about half of the richest $20 \%$ of the population, but energy expenditure-income ratio is about three times as much as the rich. Therefore, this paper will also explore the impact of pollution tax on income distribution, and how the government uses pollution tax revenue to subsidize low-carbon technologies.

\section{Model}

\subsection{Final goods sector}

According to Aghion and Howitt's (1998) endogenous growth model, there is only one final product in the economy, produced in this paper by clean and polluting production methods. 
The final product market is a fully competitive market, using a range of intermediates and labor to product. Intermediate products are produced and sold exclusively by the latest innovators, and innovation is a vertical innovation. The final product is used for investment, consumption and investment in research and development. Each period the output of the final product $\mathrm{Y}$ is expressed as:

$$
Y=Y_{c}+Y_{d}
$$

Where $Y_{c}$ represents the output of the production by clean process, while the $Y_{d}$ represents the output of the production by pollution process. The two production modes exist simultaneously, which are expressed as:

$$
Y_{c}=L_{c}^{1-a} \int_{0}^{1} A_{c i} x_{c i}^{a} d i \text { and } Y_{d}=L_{d}^{1-a} \int_{0}^{1} A_{d i} x_{d i}^{a} d i
$$

Where $0<\mathrm{a}<1, \mathrm{~A}_{\mathrm{ci}}$ and $\mathrm{A}_{\mathrm{di}}$ are productivity parameters of the intermediate product of the i-th clean and dirty production process in the current period, $\mathrm{L}_{\mathrm{ci}}$ and $\mathrm{L}_{\mathrm{di}}$ are the relevant labor allocation number, total labor $\mathrm{L}=\mathrm{L}_{\mathrm{ci}}+\mathrm{L}_{\mathrm{di}}, \quad \mathrm{x}_{\mathrm{ci}}$ and $\mathrm{x}_{\mathrm{di}}$ are the relevant intermediate input. The price of the final product is set to 1 as the valuation standard, and the equilibrium price of the $\mathrm{i}$-th intermediate product at each moment is equal to its marginal output:

$$
p_{c i}=a L_{c}^{1-a} A_{c i} x_{c i}^{a-1} \text { and } p_{d i}=a L_{d}^{1-a} A_{d i} x_{d i}^{a-1}
$$

\subsection{Intermediates sector}

The intermediates sector is a monopolistic market that is monopolized by both clean and dirty manufacturers with the most advanced technologies until they are replaced by the next innovator. Both of two manufacturers exist before clean technology completely replace pollution technology. The input of intermediate goods only requires capital, and its function is:

$$
x_{c i}=\frac{K_{c i}}{A_{c i}} \text { and } x_{d i}=\frac{K_{d i}}{A_{d i}}
$$

Where $\mathrm{K}_{\mathrm{ci}}$ and $\mathrm{K}_{\mathrm{di}}$ are the capital invested in quantity of intermediate product $\mathrm{x}_{\mathrm{ci}}$ and $\mathrm{x}_{\mathrm{di}}$.

It can be seen that as the productivity of technology increases, the capital required for production will also increase. Assuming that the cost of capital is the interest rate $\mathrm{r}$, the maximum profit of intermediate producer is:

$$
\max _{c i}=\max _{x_{c i}}\left\{p_{c i} x_{c i}-A_{c i} x_{c i} r\right\} \text { and } \max \Pi_{d i}=\max _{x_{d i}}\left\{p_{d i} x_{d i}-A_{d i} x_{d i} r\right\}
$$

After taking (2) into (4), the first-order condition can be used to obtain the maximum profit yield of the intermediate product is:

$$
x_{c i}=L_{c}\left(\frac{r}{a^{2}}\right)^{\frac{1}{a-1}} \text { and } x_{d i}=L_{d}\left(\frac{r}{a^{2}}\right)^{\frac{1}{a-1}}
$$

The profit of the monopolist after bringing (5) to (4) is:

$$
\Pi_{c i}=(1-a) a L_{c}^{1-a} A_{c i} x_{c i}^{a} \text { and } \Pi_{d i}=(1-a) a L_{d}^{1-a} A_{d i} x_{d i}^{a}
$$

Where $A_{c}$ is the production parameter of clean intermediate sector, and $A_{d}$ is that of dirty intermediate sector:

$$
A_{c}=\int_{0}^{1} A_{c i} \text { diand } A_{d}=\int_{0}^{1} A_{d i} d i
$$

From (3) and (7) we could know the capital requirement of the both two sectors :

$$
K_{c}=\int_{0}^{1} A_{c i} x_{c i} d i=A_{c} x_{c} \text { and } K_{d}=\int_{0}^{1} A_{d i} x_{d i} d i=A_{d} x_{d}
$$

Then capital intensity is:

$$
k_{c}=\frac{K_{c}}{A_{c}}=x_{c} / L_{c} \text { and } k_{d}=\frac{K_{d}}{A_{d}}=x_{d} / L_{d}
$$

\subsection{The government}

The government imposes a tax on dirty production in order to deteriorate the trend of environmental pollution and support clean technology development. Suppose the tax rate is $\tau$, the total production output becomes:

$$
Y=(1-\tau) Y_{d}+Y_{c}
$$

The government's taxation leads to the reduction of dirty process output $Y_{d}$, which has affected household expenditure. For tax revenues, the government can choose to subsidize research of clean production technologies, or to subsidize consumption to offset the impact of tax collection on household consumption. The government's budget constraint equation is:

$$
\tau Y_{d}=G=G_{c}+G_{A}, G_{A}=\theta G=\theta \tau Y_{d}, G_{C}=(1-\theta) G=\theta \tau Y_{d}
$$

Where $\tau Y_{d}$ is the government income through the pollution tax policy, $G_{c}$ is the subsidies for consumption, $G_{A}$ is the subsidies for clean technology research and development. 


\subsection{Household and environment}

The utility of the household is inextricably linked to the quality of the environment, and environmental quality can also be considered a kind of capital.

Without considering the population growth, we assume that the household in the economy has an infinite life, and the utility of the household is based on the quality of consumption and the environment. The maximum utility function is:

$$
\max U=\int_{0}^{+\infty}\left[\frac{C^{1-\sigma}-1}{1-\sigma}+v\left(S_{t}\right)\right] e^{-\rho t} d t
$$

Where $\mathrm{C}$ represents the consumption of the household, $\rho$ is discount rate, $\sigma$ is the reciprocal of the replacement elasticity of consumption over time. $\mathrm{S}$ represents the environmental stock which is determined by the dirty production output $Y_{d}$ and environmental self-healing capabilities:

$$
S_{t+1}-S_{t}=-\vartheta Y_{d t}+\omega S_{t} \quad(13)
$$

Where 9 is the marginal loss caused by the pollution of the environmental stock, $\omega$ is the self-repair ability of the environmental stock. Referring to the setting of Aghion et al (2012), we set the interval on the right side of equation $(13)$ to $(0, \bar{S})$ and the maximum value of the stock is equal to the initial value of "no pollution" before the existence of industrial activity on the earth. And meet the Inada conditions:

$$
\lim _{C \downarrow 0} \frac{\partial u(C, S)}{\partial C}=\infty \lim _{S \downarrow 0} \frac{\partial u(C, S)}{\partial C}=\infty \lim _{S \downarrow 0} u(C, S)=-\infty
$$

That is to say, in the case of very poor environmental quality, even if the consumption is high, the overall utility of the family cannot be improved. Due to the existence of environmental constraints, environmental quality can also be regarded as part of total capital. As the capital accumulates with dirty production activities, the externality of its pollution causes the loss of some invisible assets. Assuming that the environmental asset coefficient is expressed as a function of the environmental stocks $s_{\mathrm{t}}=F(\mathrm{~S})$, the household's consumption choice is limited by its wealth constraints, and its budget constraint equation is:

$$
\dot{K}=Y_{c t}+(1-\tau) Y_{d t}-C_{t}-N_{t}-s_{t} K_{t}-g_{t} K_{t}
$$

Where $\mathrm{N}_{\mathrm{t}}$ is the part of the final product that is invested in the $\mathrm{R} \& \mathrm{D}$ department, $g_{t}$ is the growth rate in a balanced state, $g_{t} K_{t}$ is the capital demand that increases with growth, and the $s_{t} K_{t}$ is environmental assets that is reduced from pollution production.

\section{$3.5 R \& D$ department}

From equation (13) we can see that the ability of environment self-recover is determined by $\omega \mathrm{S}_{\mathrm{t}}$. This equation also shows that the environmental self-repair ability will become lower and lower with the destruction of the environment. When the production activity is mainly dominated by dirty production, if the growth $\operatorname{rateg}_{t}$ of $Y_{d t}$ is greater than the rate of environmental recovery $\omega$, then the negative term on the right side of equation (13) will be greater than the positive term to reduce the environmental stock $S_{t}$, and the rate of environmental recovery depends on the current period $S_{t}$. The stock makes the decline faster and faster, eventually causing environmental disasters. Therefore, effective policies should be taken as soon as possible to resist polluting production and promote clean technology research and development. According to the setting of the endogenous growth model of Aghion and Howitt (1998), the R\&D department conducts vertical innovation. When the $\mathrm{N}_{\mathrm{t}}$ units final product is put into a research and development department, the probability of innovation will be subject to a Poisson process:

$$
\phi=\lambda N_{t}, n_{t}=\frac{N_{t}}{A_{t}^{\max }}, \lambda>0
$$

Equation (16) applies to both the clean and dirty production R\&D department, where $\lambda$ is the R\&D efficiency of the $R \& D$ department. $n_{t}$ is the $R \& D$ intensity, which is the productivity parameter divided by the most advanced technology $A^{\max }\left(A^{\max }=A_{c}^{\max }+A_{d}^{\max }\right)$, which shows the increasing $\mathrm{R} \& \mathrm{D}$ investment is required to maintain R\&D intensity for the most advanced technologies development. From (6)(9)(16), it can found that the expected return $V_{c}$ of the research and development of the clean enterprise and the expected return $V_{d}$ of the dirty companies:

$$
\begin{aligned}
& V_{c}=\int_{0}^{+\infty}\left[a(1-a) A_{c}^{\max } L_{c} k_{c}^{a}+G_{A}\right] e^{\left[-\int_{t}^{\beta}\left(r_{s}+\phi_{s}\right) d s\right] d \beta} \\
& V_{d}=\int_{0}^{+\infty}(1-\tau) a(1-a) A_{d}^{\max } L_{d} k_{d}^{a} e^{\left[-\int_{t}^{\beta}\left(r_{s}+\phi_{s}\right) d s\right] d \beta}
\end{aligned}
$$


The discount rate takes into account the interest rate and the probability of innovation. The research and development of cleaning companies is subsidized by the government $\mathrm{G}_{\mathrm{A}}$, and the expected return of research and development of polluting manufacturers will be reduced due to pollution tax. We suppose the subsidy is:

$$
G_{A}=\theta \tau Y_{d}=\eta \Pi_{c}
$$

From (17) and (18), we have:

$$
\begin{aligned}
V_{c} & =\frac{\lambda(1+\eta)(1-a) a A_{c}^{\max } L_{c} k_{c}^{a}}{r+\lambda n} \\
V_{d} & =\frac{\lambda(1-\tau)(1-a) a A_{d}^{\max } L_{d} k_{d}^{a}}{r+\lambda n}
\end{aligned}
$$

It can be seen that when the productivity parameters of polluting manufacturers $A_{d}^{\max }>A_{c}^{\max }$, if there is no pollution tax policy and research and development subsidies, the expected benefits of conducting polluting innovations are greater than that of clean innovations, so that research and development will continue to develop into pollution production, and ultimately leads to the environmental disasters. In order to promote the development of research and development in the direction of cleaner production, the pollution tax rate should at least have $\frac{\mathrm{V}_{\mathrm{c}}}{\mathrm{V}_{\mathrm{d}}}>1$ :

$$
\begin{array}{r}
\frac{V_{c}}{V_{d}}=\frac{(1+\eta)}{(1-\tau)} \times \frac{A_{c}^{\max }}{A_{d}^{\max }} \times \frac{L_{c}^{1-a}}{L_{d}^{1-a}} \times \frac{k_{c}^{a}}{k_{d}^{a}}>1 \\
\tau_{\min }>1-(1+\eta) \frac{A_{c}^{\max } L_{c}^{1-a} k_{c}^{a}}{A_{d}^{\max } L_{d}^{1-a} k_{d}^{a}}
\end{array}
$$

It can be seen that the minimum pollution tax $\tau_{\min }$ that can make the development direction toward low-carbon clean technology at each moment,which is affected by the proportion of the advanced level of the two technologies in the current period, as well as the scale of the two productions and the proportion of capital investment. The poorer clean production technology and economies, the higher the pollution tax rate required for their transformation. When $\tau>\tau_{\min }$, the growth rate of $A_{c}^{\max }$ is greater than $A_{d}^{\max }$, leading to the $\tau_{\min }$ gradually decreased. In addition, subsidies for clean technology $G_{A}$ can reduce the tax rate of the minimum pollution tax required, and to some extent reduce the distortion caused by tax collection. On the other hand, the increase of $G_{A}$ will also reduce the government's subsidies for consumption $G_{C}$, thereby increasing the impact of tax collection on household consumption.

\subsection{Technology development}

The growth of the most advanced technological productivity parameters $A_{t}^{\max }$ is caused by the knowledge spillover effect of innovation. Assuming that the speed of technology progress is directly proportional to the probability of occurrence of innovation, the rate of progress $g_{A}$ of the most advanced technology can be expressed as:

$$
g_{A}=\frac{A_{t}^{\max }}{A_{t}^{\max }}=\omega \lambda n_{t}
$$

Where $\omega>0$ indicates the marginal contribution of each innovation to the parameters of technological progress, and the rate of technological progress will increase as the intensity of $R \& D$ investment increases. It can be proved that when time tends to be infinite:

\subsection{Competitive equilibrium}

$$
A_{t}^{\max }=(1+\omega) A_{t}
$$

According to the above results, the parameters in the family's budget constraint equation (15) are respectively divided $A_{t} L$ to obtain the respective "unit effective labor parameters", which can be rewritten as:

$$
\dot{k_{t}}=y_{c t}+(1-\tau) y_{d t}-c_{t}-(1+\omega) n_{t} / L-s_{t} k_{t}-g_{t} k_{t}
$$

According to the family utility equation (12), we have:

$$
\dot{c}_{t}=c_{t}\left[(r-\rho) / \sigma-s_{t}-g_{t}\right]
$$

It can solve the stable growth path of the saddle point. The growth rate of the parameters $\left\{Y_{t}, A_{t}, A_{t}^{\max }, K_{t}, N_{t}, C_{t}\right\}$ on the balanced growth path are all equal constants, and the growth rate on the equilibrium growth path is obtained according to (24):

$$
g=g_{A}=g_{N}=g_{C}=g_{K}=\omega \lambda n_{t}
$$

According to Fisher's equation and equation (5), we have:

$$
r=\sigma \omega \lambda n+\rho=a^{2} k^{a-1}
$$




$$
n=\frac{a^{2} k^{a-1}-\rho}{\sigma \omega \lambda}
$$

According to (17) and (18), the overall R\&D discount marginal income equation is

$$
n=\frac{\lambda\left[(1+\eta)(1-a) a A_{c}^{\max } L_{c} k_{c}^{a}+(1-\tau)(1-a) a A_{d}^{\max } L_{d} k_{d}^{a}\right]-\rho}{\lambda(\sigma \omega+1)}
$$

Which could be represented by a graph:

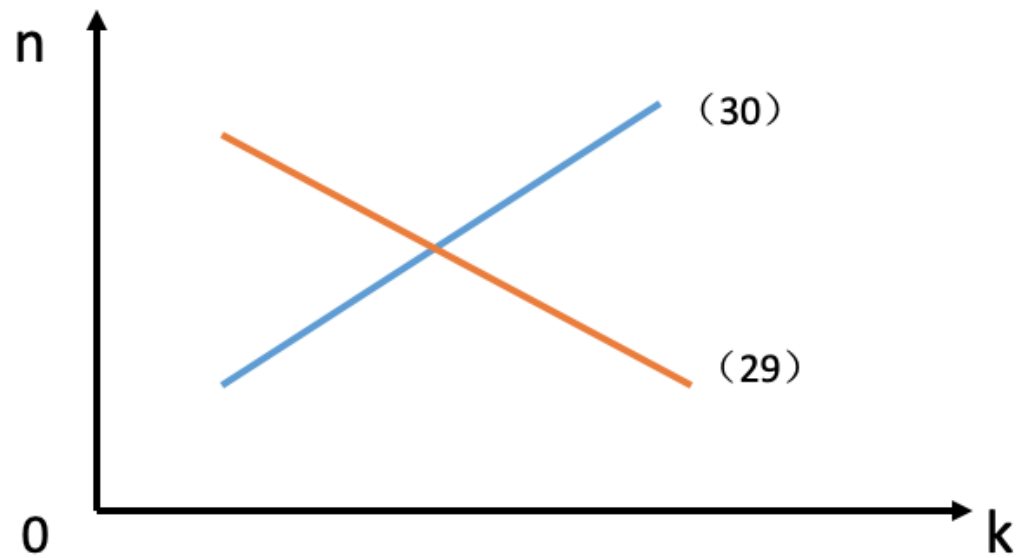

Figure 2. Changes in capital equation (29) and $R \& D$ arbitrage equation (30) with capital investment on a balanced growth path

It can be seen from the figure 2 that as the pollution tax rate increases, the output of polluting enterprises is suppressed, and the slope of the overall equation (30) will tilt to the lower right, reducing the overall $R \& D$ intensity of the economy. As the strength of $R \& D$ and the growth rate are positively correlated, the overall economic growth rate declines. However, the use of pollution taxes received from polluting companies to subsidize the research and development of cleaning companies will effectively curb the decline in this R\&D intensity. When $\tau>\tau_{\min }$, the direction of technology research and development was developing towards the development of clean technology. The scale of polluting enterprises will gradually decrease, and the impact of pollution tax will be gradually reduced, so that the economy can guarantee the environmental quality and lowcarbon transformation, then gradually return to rapid growth.

\section{Empirical Research}

\subsection{Research methods and data selection}

This paper uses the Sigh Restriction-based (SVAR) model to study the impact of environmental taxes on lowcarbon transitions and wealth distribution by using the data from French. Compared with the previous parameter constraint method, the symbol constrained SVAR developed by Uhlig (2005) does not need to constrain the parameters or the impact effect itself, only need to discriminate the direction of the impact, so the assumption is relatively less strict.

In the choice of data, this paper selects the 20-year pollution tax rate in France from 1995 to 2014, technology investment, economic growth and wealth distribution data. Due to the continuous changes in the taxes imposed by the state on environmental pollution, in order to comprehensively consider the impact of pollution taxes and fees, this paper selects the "environment-related tax-to-GDP ratio" indicator in the OECD database to reflect the national tax rate. For the indicators of technological development and transformation, this paper chooses to use the ratio of clean energy $R \& D$ investment and polluting energy $R \& D$ investment in the IEA database. Clean energy R\&D investment data selects "renewable energy R\&D investment" under the subject, while polluting energy R\&D investment data selects "fossil energy R\&D investment" data. From the initial observation of R\&D investment data, France is strengthening $R \& D$ investment in clean energy, and the ratio of $R \& D$ investment in renewable energy and fossil energy is increasing year by year. In order to analyze the impact of pollution tax policy on family wealth distribution, this paper divides French per capita wealth into 10 grades according to the position of holding wealth in the country according to the data of WID database, from the lowest $10 \%$ of wealth to the highest $10 \%$. The number of wealth per capita at this level. Correspondingly, this paper selects the per capita GDP growth rate as an indicator of economic growth rate $g_{G D P}$. 


\subsection{Symbol constraint setting}

The study will consist of two parts, first analyzing the links between economic growth $g_{G D P}$, tax rates $\tau$, and technological development transformation $N_{c} / N_{d}$. According to previous theoretical framework research, the increase in environmental tax rate should have a positive impact on technology transformation, and temporarily a negative impact on economic growth.

The symbol relationship between the three parameters in France is set as shown in the following table. The impact symbol of the row parameter on the column parameter is:

Table 1: Symbol Constraints Table for Technology Transformation

\begin{tabular}{|c|c|c|c|}
\hline Group 1 & $g_{G D P}$ & $\tau$ & $N_{c} / N_{d}$ \\
\hline$g_{G D P}$ & + & - & + \\
\hline$\tau$ & - & + & + \\
\hline$N_{c} / N_{d}$ & + & - & + \\
\hline
\end{tabular}

The second part of the empirical study will analyze the interaction between economic growth $g_{G D P}$, tax rates $\tau$ and wealth distribution. Wealth will be divided into 10 levels according to the amount of wealth held, and each person will receive the amount of wealth per person. P01 represents the average wealth of the $10 \%$ of the population with the least wealth, p12 represents the average value of the wealth of $10 \%-20 \%$ of the population, and so on. This classification is used to analyze the different impacts of pollution taxes on per capita wealth levels. According to the previous theoretical framework research, the increase of pollution tax rate should be a negative impact on per capita wealth. The symbolic relationship between the three parameters in France is set as follows. The impact symbol of row parameters on column parameters is:

Table 2: Symbol Constraints Table for Wealth Allocation

\begin{tabular}{|c|c|c|c|}
\hline Group 2 & $g_{G D P}$ & $\tau$ & wealth \\
\hline$g_{G D P}$ & + & - & + \\
\hline$\tau$ & - & + & - \\
\hline wealth & + & - & + \\
\hline
\end{tabular}

\subsection{Analysis of impulse response results}

\subsubsection{Low-carbon transition}

After causality test and stationarity test, the symbolic identification data of the first group of French technology transformation was analyzed in Matlab using the symbol recognition SVAR method.

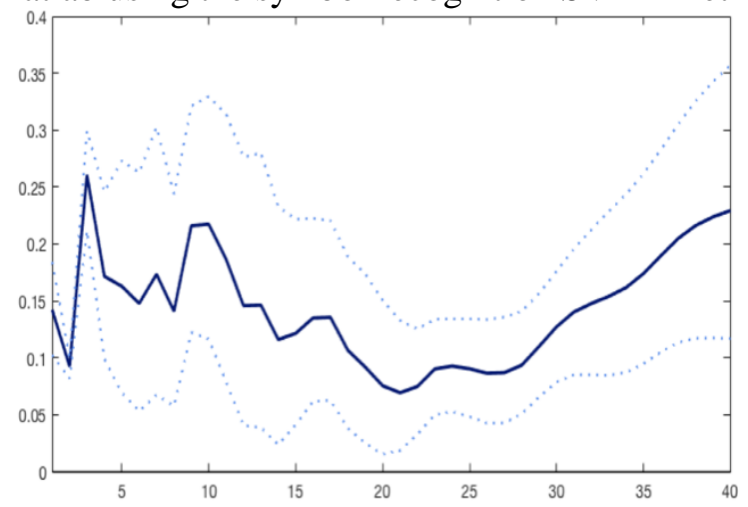

Figure 3.Environmental tax rate shock response to $R \& D$ transformation 


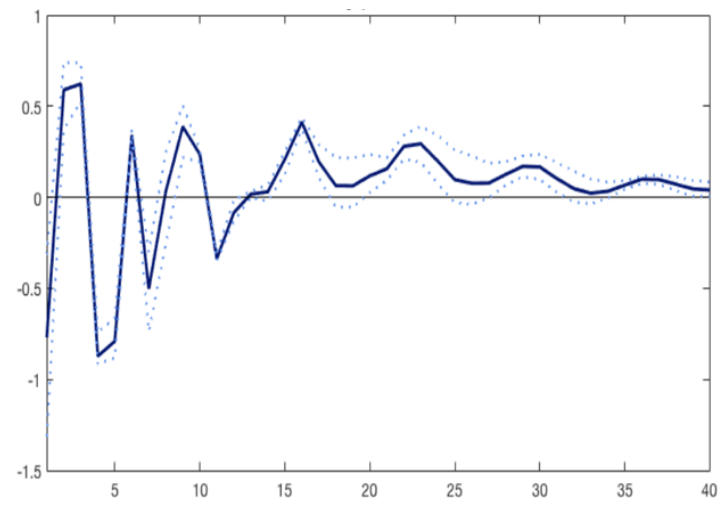

Figure 4. The impulse response of environmental tax rate shock to economic growth rate

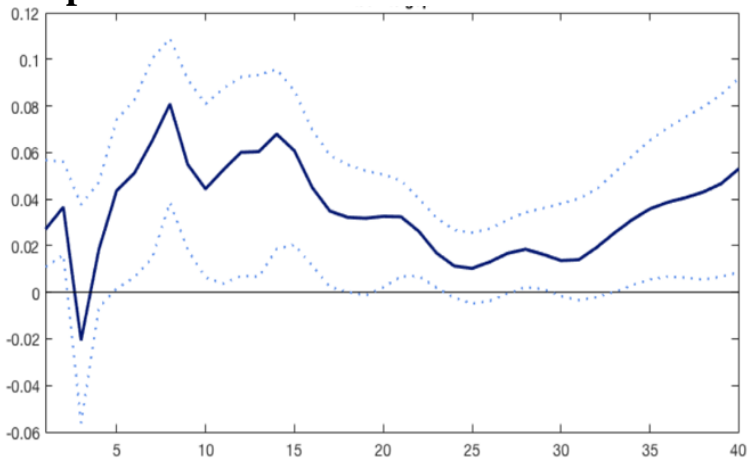

Figure 5.The impact of economic growth rate on the impulse response of technological transformation

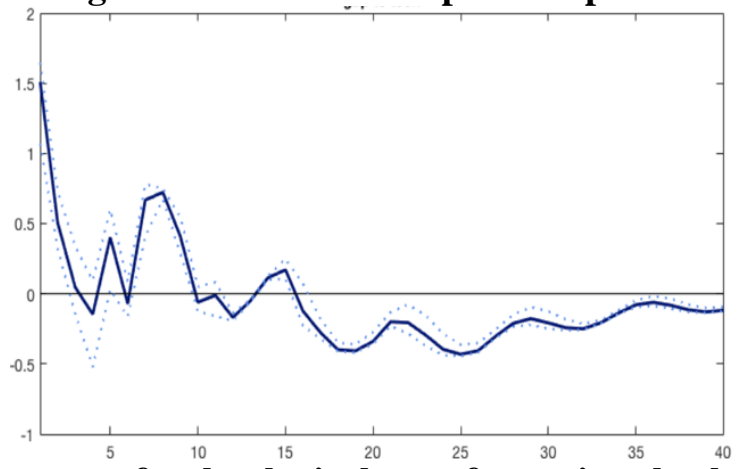

Figure 6.The impulse response of technological transformation shock to economic growth rate

Figure 3-6 lists the relationship between several parameters that are of interest in this paper for all impulse response results. As can be seen from Figure 3.1, the change in the environmental pollution tax rate has been positively affecting the transformation of clean technology since the impact period, which reflects the rapid response of enterprises to the price shock brought by tax collection, and the policy response The long-term driving role of clean technology development. Figure 3.2 shows the impact of environmental tax on economic growth. It can be seen from the figure that environmental tax as a price shock has a significant impact on economic growth in the early stage. The initial shock of economic growth rate may be due to the impact of price shocks. Adjustment. In the long run, with the deepening of technological transformation, the impact of environmental taxes on the economy will gradually weaken. Figure 3.3 shows that economic growth is positively driving technology transformation, and more capital can be used for clean technology research and development due to economic growth. On the other hand, the effect of technological transformation on economic growth in Figure 3.4 is not obvious, and it will even drag down economic development in the long run. This may be due to the fact that France developed clean energy earlier and is already in a more advanced stage of cleaner production technology. Therefore, the difficulty of developing clean production technology and the increasing capital required for investment are difficult to promote economic growth.

\section{(2) Wealth distribution effect}


The results of the first part of the empirical study on technology transformation are basically similar to those of the previous theoretical model. Now this paper will analyze the impact of environmental tax on the distribution of residents' wealth.

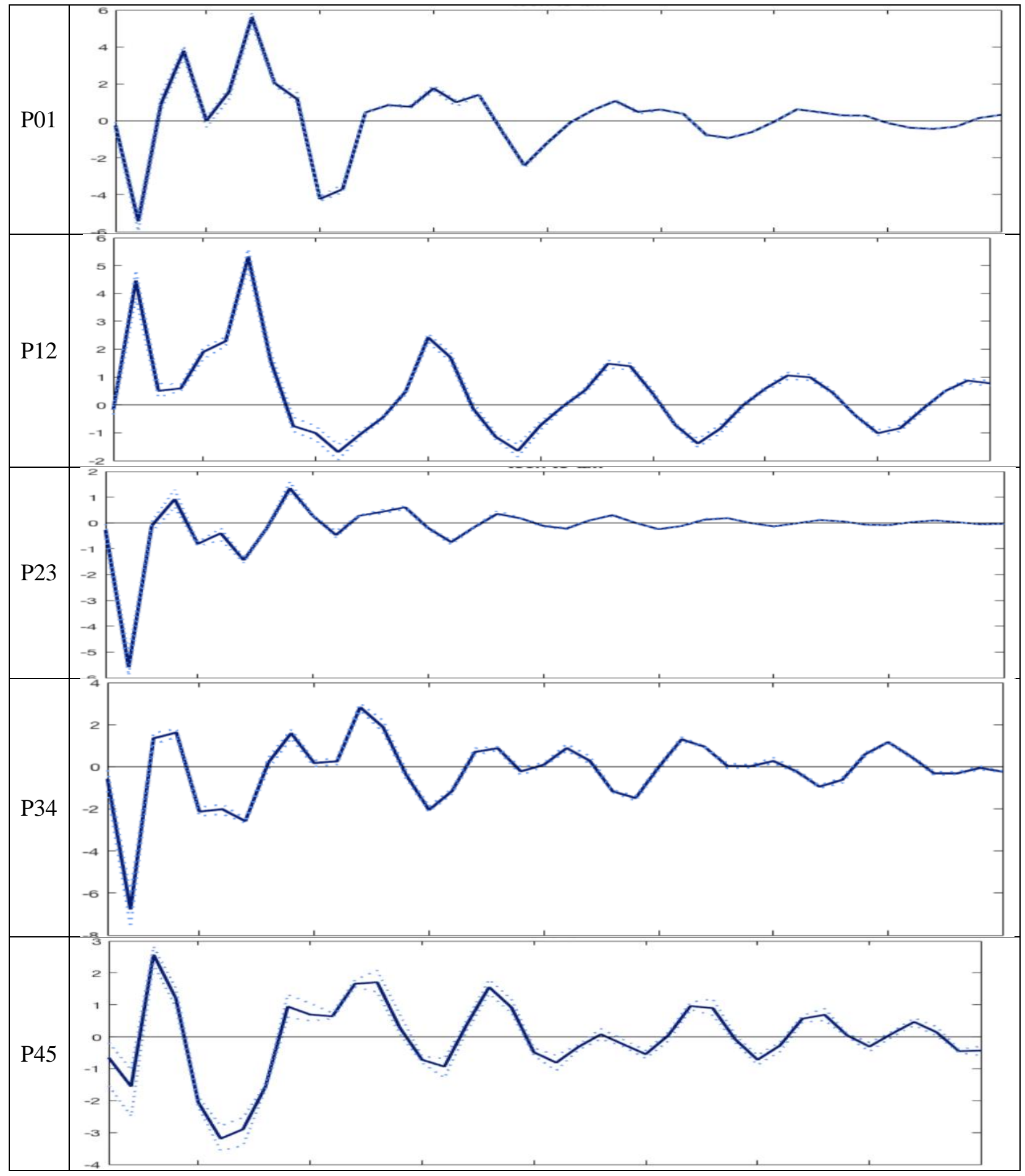




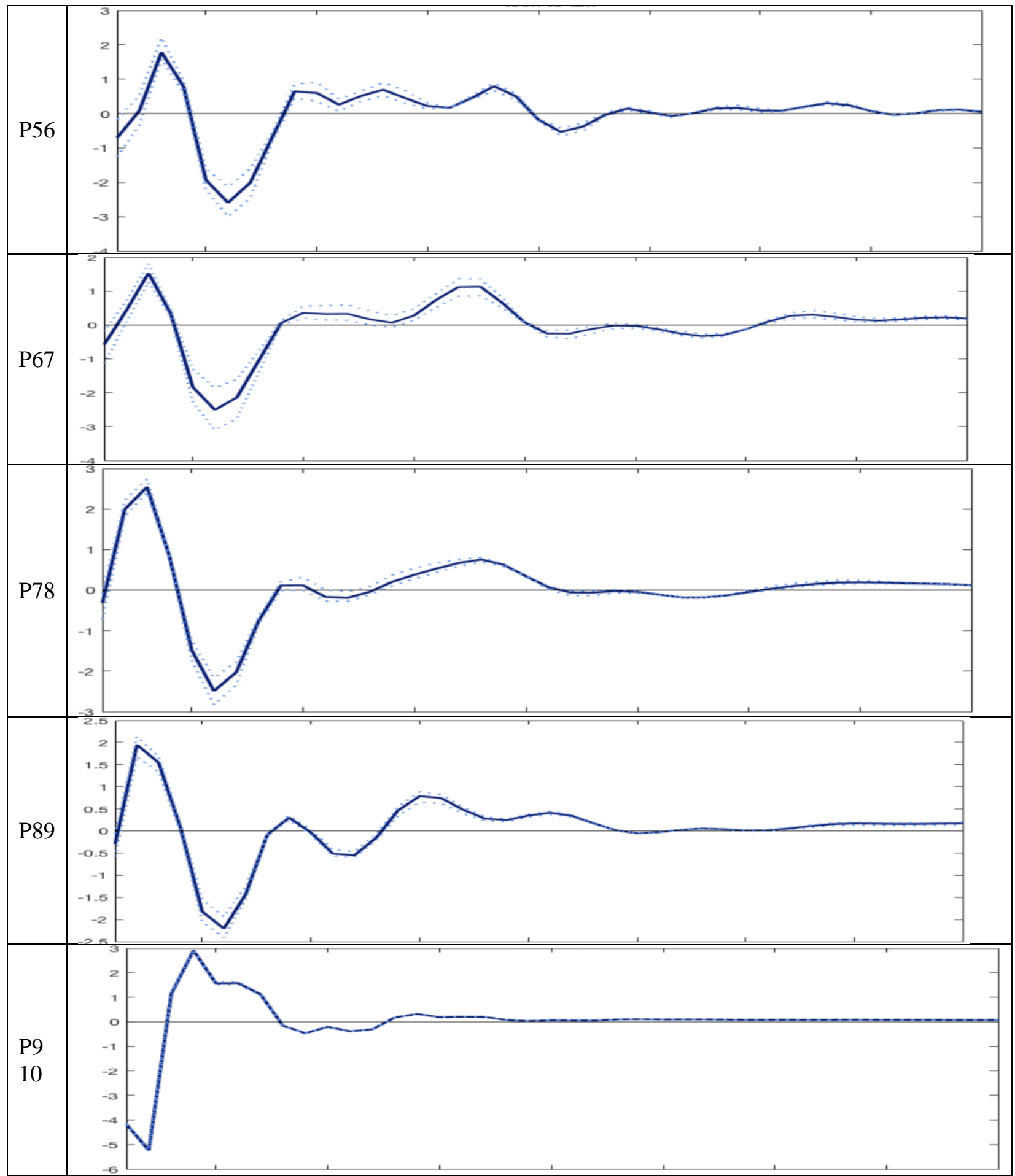

Figure 7. Impulse response of environmental taxes to different wealth levels

Figure 4 shows the impulse response of environmental taxes to people of different wealth levels. It is divided into 10 groups, of which P01 represents the lowest 10\% of the population, and so on to P910 which represents the highest level of wealth. It can be seen from the figure that environmental taxes have a negative impact on different groups of people during the impact period, and this impact gradually disappears with time. But the difference is that the speed at which this shock disappears is clearly accelerating as the level of wealth increases. It reflects that the price shock brought by environmental taxation is longer for low-income people, and this policy may increase the inequality of social wealth. In addition to the difference in the length of the impact of wealth shocks, the extent of the impact on income distribution does not reflect a clear trend of changes in wealth levels. 
The most severely affected group was the two groups P23 and P34. It might be attributed to the energy demand of these two groups is relatively largethan the lower wealth people.

\section{Conclusion}

This paper examines the impact of pollution tax policies on the development of cleaner production technologies in the background of global warming. Based on the endogenous economic growth model of Aghion and Howitt (1998), this paper first discusses how to use environmental tax policies to promote the transition to cleaner production when both polluting and clean production models exist simultaneously and polluting production techniques are more advanced.The conclusion proves that the way of taxing pollution production can effectively tilt the company's research and development direction toward clean technology and give the lowest tax rate to achieve this effect. The tax rate is determined by the technical productivity, market size and capital investment level of the two different production models in the current period. With the deepening of technological transformation, the increase in the scale of the cleantech production market and the increase in capital investment in clean enterprises, the environmental taxes required are also reduced, and the distortion of the taxation on the economy is gradually reduced. The government can also use the environmental tax revenues received from polluting companies tosubsidies for clean production companies. This will further reduce the tax rate of the minimum environmental tax. On the other hand, the policy cost of pollution tax cannot be ignored.

Measures to collect taxes on pollution will inhibit the production activities of polluting enterprises and reduce the economic growth rate during the transition period. In addition, the tax policy has a greater impact on energyintensive companies related to living activities such as residential heating. Therefore, it will increase the expenditure of residents in these aspects, especially for those with lower levels of wealth. However, as clean production technologies and markets gradually develop and gradually replace polluting enterprises, the impact of the economic pollution tax is gradually reduced, and these negative effects might be gradually eliminated.

\section{References}

Acemoglu, Daron, Philippe Aghion, Leonardo Bursztyn, and David Hémous.2012. "The Environment and Directed Technical Change.” A.E.R. 102:13166.

Acemoglu, Daron Ufuk Akcigit, Douglas Hanley, and William Kerr. 2016. "Transition to Clean Tech- nology." Journal of Political Economy 124(1): 52-104.

Aghion, Philippe, and Peter Howitt. 1992. "A Model of Growth through Creative Destruction.” Econometrica 110:323-51.

Aghion, P. and P. Howitt (1998) Endogenous Growth Theory, MIT Press, Cambridge, MA.

Hassler, John, and Per Krusell. 2012. "Economics and Climate Change: Integrated Assessment in a Multi-region World.” J. European Econ. Assoc. 10 ð5P: 974-1000.

IEA data services (2017), [Online] http://wds.iea.org/WDS/TableViewer/tableView.aspx

IPCC Fifth Assessment, Science (2013). Intergovernmental Panel on Climate Change, Climate Change 2013: The Physical Science Basis, Contribution of Working Group I to the Fourth Assessment Report of the IPCC.

OECD database (2017). [Online] http://stats.oecd.org/Index.aspx

Popp, David. 2002. "Induced Innovation and Energy Prices.” A.E.R. 92:160-80.

Newell, Richard, Adam Jaffe, and Robert Stavins. 1999. "The Induced Innovation Hypothesis and Energy-Saving Technological Change.” Q. J.E. 114:941-75.

WID database(2017)[Online] http://wid.world/data 